Although in our experience television is the best method of putting over a public health education message, in the United States local newspapers are reported to be most effective. ${ }^{15} 16$ This may reflect the fact that many television channels are available to the American viewer, and as cable television spreads in the UK the balance may shift.

Because of the rapid spread of information from the west of Scotland to other parts of the country it was impossible to have a control group that was not exposed to the information. It is advisable therefore to have, as we did, data from preceding years on patients to be used as an internal control. Although the effect of such publicity on the workload in other parts of the country may have been appreciable, it was difficult to predict because of patchy and unexpected interest in areas distant from the west of Scotland and the rerunning of national radio and television programmes.

Throughout we found reporters and journalists, almost without exception, willing to have copy checked for factual accuracy before use. Copy for titles and bylines of articles were not always made available and were occasionally more dramatic and alarming than appropriate.

Seven other centres in the UK have now run similar campaigns for early detection of melanoma funded by the Cancer Research Campaign. It will be interesting to compare their experiences with ours.

We thank the Camilla Samuels Fund for financial support, Dr Doherty, the Imperial Cancer Research Fund for financial help with posters and booklets, and the Scottish Melanoma Group, funded by Scottish Home and Health Department grant No K/MRS/50/C363, for access to data. Mrs Doreen
Watson of the Greater Glasgow Health Education Group offered valuable advice and help. Throughout this study full cooperation was given by the dermatologists, pathologists, and plastic surgeons in Glasgow and Edinburgh, whom we thank.

1 Swerdlow AJ. Epidemiology of cutaneous malignant melanoma. In: MacKie RM, ed. Clinics in Oncology. Melanoma. Vol 3, No 3. London: Saunders, 1984:407-37.

2 Schreiber MM, Bozzo PD, Moon TE. Malignant melanoma in southern Arizona. Arch Dermatol 1981;117:6-11.

3 Kopf AW, Kripke ML, Stern RS. Sun and melanoma. 7 Am Acad Dermato 1984;11:674-84.

4 Breslow A. Thickness, cross-sectional area and depth of invasion in the prognosis of cutaneous melanoma. Ann Surg 1970;172:902-8.

5 MacKie RM, Soutar DS, Watson ACH, et al. Malignant melanoma in Scotland 1979-1983. Lancet 1985; ii:859-62.

6 McLeod GR. Control of melanoma in high-risk populations. In: Elwood JM Melanoma and naevi. Pigment Cell. Vol 9. Basel: Karger, 1988:133.

7 Temoshok L, Di Clemente RJ, Sweet DM, Blois MS, Sagebiel RW. Factors related to patient delay in seeking medical attention for cutaneous malignant melanoma Cancer 1984:54:3048-53.

8 Cassileth BR, Clark WH Jr, Heiberger RM, March V, Tenaglia A. Relationship between patients' early recognition of melanoma and depth of invasion. ship between patients' early

9 Kopf AW, Gross DF, Rogers GS, et al. Prognostic index for malignant melanoma. Cancer 1987;59:1236-41.

10 Urist MM, Balch CM, Soong S, Shaw HM, Milton GW, Maddox WA. The influence of surgical margins and prognostic factors predicting the risk of local recurrence in 3445 patients with primary cutaneous melanoma. Cancer $1985 ; 55: 1398-402$

11 Breslow A. Prognostic factors in the treatment of cutaneous melanoma J Cutan Pathol 1978;6:208-12.

12 Eldh J, Boeryd B, Suurkula M, et al. Melanoma in Sweden: experience at the University of Goteborg. In: Balch CM, Milton GW, eds. Cutaneous melanoma. Philadelphia: Lippincott, 1985:473.

13 Doherty VR, MacKie RM. Reasons for poor prognosis in British patients with cutaneous malignant melanoma. Br Med 7 1986;292:987-9.

14 Arundell FD Screening for melanoma and skin cancer. FAMA 1986:255: 3443

15 Field SI. Melanoma/skin cancer screening in Michigan. 7 Am Acad Dermatol 1987; 16:578-83.

16 Olsen TG, Feeser TA, Conte ET, Schroeter AL. Skin cancer screeninglocal experience. 7 Am Acad Dermatol 1987; 16:637-41.

Accepted 25 May 1988)

\section{Department of \\ Epidemiology, London \\ School of Hygiene and \\ Tropical Medicine, \\ London WC1E 7HT \\ Adèle Green, PHD, research \\ fellow \\ Valerie Beral, MRCP, reader \\ Social Statistics Research \\ Unit, City University, \\ London ECIV OHB \\ Kath Moser, MSC, research \\ fellow}

Correspondence to:

Dr Beral.

\title{
Mortality in women in relation to their childbearing history
}

\author{
Adèle Green, Valerie Beral, Kath Moser
}

\begin{abstract}
With data from the Office of Population Censuses and Surveys' longitudinal study the mortality of currently married women aged under 60 in 1971 was investigated in relation to the number of liveborn children reported at the 1971 census, adjusting for their husbands' social class. Women who had never had children experienced a higher mortality from many causes of death than the parous women, and this was probably due, at least in part, to selective factors. When the analysis was confined to parous women mortality from diabetes mellitus and cervical cancer increased significantly and oesophageal cancer decreased significantly with increasing number of liveborn children. Mortality from all circulatory diseases and from hypertensive disease, ischaemic heart disease, and subarachnoid haemorrhage tended to rise with parity, though the trends were not statistically significant. Mortality from breast cancer decreased significantly with the number of liveborn children, but only when nullipara were included in the analyses.
\end{abstract}

These data suggest that there may be residual and cumulative effects of childbearing which influence patterns of disease in the long term.

\section{Introduction}

The relation between a history of childbearing and women's health in the long term has been little studied, except for cancers of the reproductive organs. The risk of breast, ovarian, and endometrial cancers is lower and the risk of cervical cancer higher in women of high parity than in nulliparous women..$^{1-3}$ It has been suggested that the risk of gastric ${ }^{13}$ and possibly brain ${ }^{2}$ cancer may increase with the number of children a woman has had, but few studies have investigated these relations. The evidence about cancer of the colon is conflicting, some researchers reporting a decreasing risk with increasing parity ${ }^{45}$ and others finding no relation. ${ }^{26}$

Among married women the parous have been found to experience an excess mortality from ischaemic heart disease, nephritis and nephrosis, diabetes mellitus, and cerebrovascular disease compared with the nulliparous. ${ }^{3}$ Findings from case-control studies of women with coronary heart disease ${ }^{78}$ and diabetes mellitus ${ }^{9}$ suggest that the relative risk of each condition increases with the number of children a woman has had, but these findings are from small studies of selected women

There are no data which systematically relate women's reproductive history to their long term health. Furthermore, some of the associations described might be confounded by socioeconomic class. For example, the association between stomach cancer or ischaemic heart disease and high parity might be because these conditions and high parity are more common in the lower social classes; and the association between breast, ovarian, or endometrial cancer and nulliparity might be because those conditions and nulliparity are more common in the higher social classes. ${ }^{10}$ 
Using data from the Office of Population Censuses and Surveys' longitudinal study we investigated the relation between parity and mortality from a range of causes in currently married women, adjusting for their husbands' social class.

\section{Subjects and methods}

The Office of Population Censuses and Surveys' longitudinal study was initiated as a $1 \%$ sample of the 1971 census population to which subsequent routinely collected information on events such as deaths and cancer registration have been added..$^{10}$ In the census women aged under 60 who had ever been married were asked to state the number of live children born to them in marriage. We refer to this as the woman's "parity," although it excludes any stillbirths or illegitimate children that she may have borne. The numbers of these would probably not affect the analyses presented in this paper. The question on parity in the census was answered by 108352 women from the longitudinal study sample who were aged 16-59 and had ever been married, a response rate of $96 \%$.

These analyses focus on women who were married at the time of the census with a stated parity. Women whose husbands' occupation was recorded on the census schedule were classified according to their husbands' social class. Those who could not be classified in this way were excluded from the analyses; they included women whose husbands were in the armed forces or unoccupied or whose occupation was inadequately described, as well as women whose husbands were not present in the household at the census. The mortality of women who were currently married and aged 16-59 at the 1971 census was analysed up to census day 1981. There were 3298 deaths in those with a stated parity and a husband in social classes I-V.

The mortality experience of the women of parities 0 , $1,2,3,4$, and 5 or more is expressed as a standardised mortality ratio, which is the ratio (multiplied by a factor of 100) of observed numbers of deaths in each parity group to the number expected on the basis of death rates in the standard population. To standardise for the age and social class distribution of each parity group we applied age and social class specific death rates (in five year age groups and in four social class groups: I and II; III (non-manual); III (manual); IV and $\mathrm{V}$ ) for all currently married women to the person years at risk for that age, social class, and parity group. The expected deaths were summed over all ages and social classes and compared with the corresponding observed deaths for each parity group. The signific- ance of the association between mortality and number of children was assessed by a two sided $\chi^{2}$ test for linear trend" for all women and for all parous womenthat is, those who reported at least one live birth. Standardised mortality ratios for some selected causes within different social class groups are also presented.

\section{Results}

Standardised mortality ratios by parity, adjusted for age and social class, were calculated for all causes of death and selected non-malignant causes (table I) and for selected malignancies (table II).

In focusing on currently married women with a stated parity and a husband in social class $I$ to $V$ we excluded certain women from tables I and II. These were married women who failed to respond to the census question on parity (who had an all cause standardised mortality ratio of 129 (95\% confidence interval 111 to 149)) and women whose husbands' occupations could not be classified into social classes I to $\mathrm{V}$ (who had an all cause standardised mortality ratio of 140 (95\% confidence interval 127 to 154$)$ ).

Nulliparous married women had an all cause standardised mortality ratio of 113 , which was significantly higher $(\mathrm{p}<0.01)$ than the standardised mortality ratio of 97 for parous married women, and their higher mortality was observed for many of the causes of death analysed. Because the high mortality in nulliparas might have been the result of selective processes, as discussed below, we focused mainly on the trends in mortality with increasing numbers of live births among parous women.

Among specific non-malignant conditions in parous women (table I) the mortality ratios for diabetes mellitus rose significantly $(p<0.001)$ with increasing parity, from a standardised mortality ratio of 57 among women who had one child to one of 274 among women with five or more children. The mortality for all circulatory diseases and specific conditions such as hypertensive disease, ischaemic heart disease, subarachnoid haemorrhage, and nephritis and nephrosis increased with parity, though the trends were not significant and the relative increase in mortality according to number of children was small. The mortality from digestive diseases showed no clear relation to parity, while deaths from accidents, poisonings, and violence decreased slightly, but not significantly, as parity increased.

Among malignant conditions in parous women (table II) cervical cancer showed a significantly increasing trend $(p<0.05)$ and oesophageal cancer a significantly decreasing trend $(p<0.05)$ with

TABLE I-Standardised mortality ratios (and numbers of deaths observed) in women currently married $†$ and aged 16-59 in 1971 by parity $\neq$ and cause of death, adjusted for social class, 1971-81

\begin{tabular}{|c|c|c|c|c|c|c|c|c|}
\hline \multirow[b]{2}{*}{ Cause of death (ICD- 8 code) } & \multicolumn{6}{|c|}{ Parity } & \multicolumn{2}{|c|}{$\chi^{2}$ Test for trend } \\
\hline & 0 & 1 & 2 & 3 & 4 & $\geqslant 5$ & $\begin{array}{c}\text { All } \\
\text { parous women }\end{array}$ & $\begin{array}{c}\text { All } \\
\text { women }\end{array}$ \\
\hline All causes & $113(505)$ & $98(809)$ & $95(991)$ & $93(515)$ & $99(241)$ & $108(237)$ & 0.95 & 0.93 \\
\hline Diabetes mellitus ( 250$)$ & $167(8)$ & $57(5)$ & $28(3)$ & $89(5)$ & $248(6)$ & $274(6)$ & $15 \cdot 64^{\star \star}$ & $4 \cdot 42^{\star}$ \\
\hline Diseases of circulatory system $(390-458)$ & $103(152)$ & $104(289)$ & $88(298)$ & $95(171)$ & $112(90)$ & $121(91)$ & $2 \cdot 27$ & 0.99 \\
\hline Hypertensive disease $(400-404)$ & $84(4)$ & $46(4)$ & $100(11)$ & $119(7)$ & $305(8)$ & $41(1)$ & 2.52 & $2 \cdot 34$ \\
\hline Ischaemic heart disease $(410-414)$ & $99(76)$ & $103(150)$ & $87(151)$ & $103(96)$ & $106(44)$ & $125(50)$ & $2 \cdot 01$ & 1.43 \\
\hline Cerebrovascular disease (430-438) & $114(42)$ & $107(73)$ & $81(70)$ & $88(40)$ & $135(27)$ & $132(24)$ & 1.73 & 0.34 \\
\hline Subarachnoid haemorrhage $(430)$ & $116(14)$ & $102(22)$ & $84(24)$ & $75(11)$ & $158(10)$ & $170(9)$ & $2 \cdot 34$ & 0.88 \\
\hline Cerebral haemorrhage (431) & $131(12)$ & $110(19)$ & $70(16)$ & $106(13)$ & $72(4)$ & $158(8)$ & 0.66 & 0.002 \\
\hline Diseases of digestive system $(520-577)$ & $110(17)$ & $92(26)$ & $93(32)$ & $101(18)$ & $92(7)$ & $104(7)$ & 0.09 & 0.004 \\
\hline \multicolumn{9}{|l|}{ Diseases of liver, gall bladder, and pancreas } \\
\hline$(570-577)$ & $127(8)$ & $84(10)$ & $93(14)$ & $116(9)$ & $91(3)$ & $108(3)$ & $0 \cdot 24$ & 0.00 \\
\hline Nephritis and nephrosis $(580-584)$ & $109(9)$ & $73(11)$ & $105(20)$ & $78(8)$ & $111(5)$ & $143(6)$ & $1 \cdot 37$ & $0 \cdot 48$ \\
\hline Accidents, poisonings, and violence (800-999) & $110(26)$ & $92(36)$ & $87(47)$ & $118(33)$ & $59(7)$ & $62(6)$ & 0.49 & $1 \cdot 21$ \\
\hline Suicide $(850-877,942,950-959,980-989)$ & $125(14)$ & $89(17)$ & $93(26)$ & $103(15)$ & $48(3)$ & $80(4)$ & $0 \cdot 19$ & 1.08 \\
\hline
\end{tabular}

Significance of trend: ${ }^{\star} \mathrm{p}<0.05, \star \star \mathrm{p}<0.001$

tCurrently married to a husband in social class I-V. (Standardised mortality ratios are based on comparison with all currently married women with a husband in social class I-V; standardisation was performed by age and social class.)

$\ddagger$ Parity refers to number of live births in marriage, as recorded in 1971 census. 


\begin{tabular}{|c|c|c|c|c|c|c|c|c|}
\hline \multirow[b]{2}{*}{ Cause of death (ICD-8 code) } & \multicolumn{2}{|c|}{ • } & \multicolumn{2}{|c|}{ Parity } & \multirow[b]{2}{*}{4} & \multirow[b]{2}{*}{$\geqslant 5$} & \multicolumn{2}{|c|}{$\gamma^{2}$ Test for trend } \\
\hline & 0 & 1 & 2 & 3 & & & $\begin{array}{l}\text { All } \\
\text { parous women }\end{array}$ & $\begin{array}{c}\text { All } \\
\text { women }\end{array}$ \\
\hline All malignant neoplasms $(1+0-209$ ) & $121(231)$ & $96(341)$ & $103(475)$ & $91(221)$ & $84(90)$ & $97(93)$ & 0.72 & $5 \cdot 94 * \star$ \\
\hline Oesophageal cancer ( 150 & 108 & $158(11)$ & $95(8)$ & $69(3)$ & $54(1)$ & $0(0)$ & $4 \cdot 44^{\star}$ & $3 \cdot 29$ \\
\hline Stomach cancer $(151)$ & $116(11)$ & $99(18)$ & $98(21)$ & $105(12)$ & $137(7)$ & $60(3)$ & 0.02 & $0 \cdot 19$ \\
\hline Large bowel cancer (153) & $122(14)$ & $97(21)$ & $87(25)$ & $79(12)$ & $105(7)$ & $173(10)$ & 1.61 & $0 \cdot 35$ \\
\hline Rectal cancer $(154)$ & $120(6)$ & $62(6)$ & $106(13)$ & $121(8)$ & $167(5)$ & $36(1)$ & $0 \cdot 20$ & 0.01 \\
\hline Liver and gall bladder cance $155-156$ & $0(0)$ & $88(4)$ & $212(12)$ & $33(1)$ & $0(0)$ & $163(2)$ & $0 \cdot 22$ & $0 \cdot 28$ \\
\hline Pancreatic cancer (157) & $116(6)$ & $100(10)$ & $101(13)$ & $104(7)$ & $33(1)$ & $115(3)$ & 0.07 & $0 \cdot 20$ \\
\hline Lung cancer $(162)$ & $116(34)$ & $89(49)$ & $111(77)$ & $70(26)$ & $120(20)$ & $116(18)$ & $0 \cdot 40$ & 0.002 \\
\hline Melanoma (172) & $6+1)$ & $133(4)$ & $175(7)$ & $0(0)$ & $105(1)$ & $0(0)$ & $2 \cdot 08$ & $0 \cdot 90$ \\
\hline Breast cancer (174) & $1+4+72$ & $99(93)$ & $103(132)$ & $86(58)$ & $65(19)$ & $84(21)$ & $2 \cdot 59$ & $9 \cdot 69^{\star \star \star}$ \\
\hline Cervical cancer $(180)$ & $102(11)$ & $75(16)$ & $84(23)$ & $139(21)$ & $42(3)$ & $192(13)$ & $4 \cdot 87^{\star}$ & $3 \cdot 22$ \\
\hline Other uterine cancer $(181-182)$ & $161(6)$ & $8+(6)$ & $83(7)$ & $89(4)$ & $199(4)$ & $52(1)$ & $0 \cdot 19$ & $0 \cdot 17$ \\
\hline Ovarian cancer $(183)$ & $108(20)$ & $89(30)$ & $129(58)$ & $77(18)$ & $59(6)$ & $92(8)$ & 0.77 & 0.86 \\
\hline Other genital cancer $(184)$ & 2113 & $7+(2)$ & $63(2)$ & $116(2)$ & $0(0)$ & $137(1)$ & $0 \cdot 10$ & $0 \cdot 36$ \\
\hline Bladder and kidney cancer $(188-189)$ & $2258:$ & 1178 & $59(5)$ & $86(4)$ & $47(1)$ & $48(1)$ & 1.03 & $4 \cdot 79^{\star}$ \\
\hline \multirow{2}{*}{\multicolumn{9}{|c|}{ Brain and other central nervous system cancer }} \\
\hline & $128: 10$ & $67(9)$ & $131(23)$ & $76(7)$ & $7+(3)$ & $28(1)$ & 0.77 & 1.64 \\
\hline Thyroid cancer $(193)$ & $1+7(1)$ & $157(2)$ & $68(1)$ & $0(0)$ & $0(0)$ & $0(0)$ & 1.67 & $1 \cdot 81$ \\
\hline $\begin{array}{l}\text { All lymphatic and haematopoietic neoplasms } \\
(200-209)\end{array}$ & $79(10)$ & $117(25)$ & $79(22)$ & $104(15)$ & $115(7)$ & $140(7)$ & $0 \cdot 26$ & 0.71 \\
\hline \multirow{2}{*}{$\begin{array}{l}\text { All benign and unspecified neoplasms } \\
(210-239)\end{array}$} & & & & & & & & \\
\hline & $1+0(t)$ & $65(3)$ & $76(5)$ & $86(3)$ & $200(3)$ & $168(2)$ & $2 \cdot 29$ & 0.56 \\
\hline
\end{tabular}

Significance of trend: ${ }^{\star} \mathrm{p}<0 \cdot 05,{ }^{\star \star} \mathrm{p}<0 \cdot 025,{ }^{\star \star \star *} \mathrm{p}<0 \cdot 005$

tCurrently married to a husband in social class I-V. (Standardised mortality ratios are based on comparison with all currently married women with a husband in social class I-V; standardisation was performed by age and social class.)

$\ddagger$ Parity refers to number of live births in marriage, as recorded in 1971 census.

TABLE III-Standardised mortality ratios (and numbers of deaths observed) in women currently marriedf and aged 16-59 in 1971 by parity, $\neq$ cause of death, and social class, 1971-81

\begin{tabular}{|c|c|c|c|c|c|c|c|c|}
\hline \multirow[b]{2}{*}{ Cause of death (ICD-8 code) } & \multirow[b]{2}{*}{ Social class } & \multicolumn{6}{|c|}{ Parity } & \multirow[b]{2}{*}{ Total } \\
\hline & & 0 & 1 & 2 & 3 & 4 & $\geqslant 5$ & \\
\hline All causes & $\left\{\begin{array}{l}\text { Non-manual } \\
\text { Manual }\end{array}\right.$ & $\begin{array}{r}86(175) \\
118(330)\end{array}$ & $\begin{array}{r}79(261) \\
100(548)\end{array}$ & $\begin{array}{l}74(3+1) \\
98(650)\end{array}$ & $\begin{array}{l}78(167) \\
93(348)\end{array}$ & $\begin{array}{c}80(63) \\
101(178)\end{array}$ & $\begin{array}{c}79(37) \\
113(200)\end{array}$ & $\begin{array}{r}78(1044) \\
101(2254)\end{array}$ \\
\hline Diabetes mellitus & $\left\{\begin{array}{l}\text { Non-manual } \\
\text { Manual }\end{array}\right.$ & $\begin{array}{l}136(3) \\
172(5)\end{array}$ & $\begin{array}{l}57(2) \\
53(3)\end{array}$ & $\begin{array}{l}43(2) \\
1+(1)\end{array}$ & $\begin{array}{r}136(3) \\
53(2)\end{array}$ & $\begin{array}{r}0(0) \\
333(6)\end{array}$ & $\begin{array}{l}500(2) \\
222(4)\end{array}$ & $\begin{array}{l}87(12) \\
92(21)\end{array}$ \\
\hline Ischaemic heart disease & $\left\{\begin{array}{l}\text { Non-manual } \\
\text { Manual }\end{array}\right.$ & $\begin{array}{r}61(21) \\
113(55)\end{array}$ & $\begin{array}{c}75(44) \\
109(106)\end{array}$ & $\begin{array}{c}49(38) \\
101(113)\end{array}$ & $\begin{array}{r}48(17) \\
126(79)\end{array}$ & $\begin{array}{c}61(8) \\
12+(36)\end{array}$ & $\begin{array}{c}63(5) \\
149(45)\end{array}$ & $\begin{array}{r}59(133) \\
114(434)\end{array}$ \\
\hline Stomach cancer & $\left\{\begin{array}{l}\text { Non-manual } \\
\text { Manual }\end{array}\right.$ & $\begin{array}{c}23(1) \\
161(10)\end{array}$ & $\begin{array}{c}41(3) \\
122(15)\end{array}$ & $\begin{array}{c}51(5) \\
113(16)\end{array}$ & $\begin{array}{r}133(6) \\
75(6)\end{array}$ & $\begin{array}{r}0(0) \\
189(7)\end{array}$ & $\begin{array}{r}0(0) \\
77(3)\end{array}$ & $\begin{array}{r}52(15) \\
118(57)\end{array}$ \\
\hline Lung cancer & $\left\{\begin{array}{l}\text { Non-manual } \\
\text { Manual }\end{array}\right.$ & $\begin{array}{l}117(15) \\
107(19)\end{array}$ & $\begin{array}{l}74(16) \\
92(33)\end{array}$ & $\begin{array}{l}104(31) \\
108(46)\end{array}$ & $\begin{array}{l}14(2) \\
99(24)\end{array}$ & $\begin{array}{c}96(5) \\
130(15)\end{array}$ & $\begin{array}{c}32(1) \\
143(17)\end{array}$ & $\begin{array}{c}81(70) \\
107(154)\end{array}$ \\
\hline Breast cancer & $\left\{\begin{array}{l}\text { Non-manual } \\
\text { Manual }\end{array}\right.$ & $\begin{array}{l}130(28) \\
151(44)\end{array}$ & $\begin{array}{r}109(39) \\
92(54)\end{array}$ & $\begin{array}{r}110(59) \\
97(73)\end{array}$ & $\begin{array}{l}86(22) \\
84(36)\end{array}$ & $\begin{array}{l}74(7) \\
57(12)\end{array}$ & $\begin{array}{l}125(7) \\
68(14)\end{array}$ & $\begin{array}{r}107(162) \\
94(233)\end{array}$ \\
\hline Cervical cancer & $\left\{\begin{array}{l}\text { Non-manual } \\
\text { Manual }\end{array}\right.$ & $\begin{array}{c}19(1) \\
137(10)\end{array}$ & $\begin{array}{l}33(3) \\
87(13)\end{array}$ & $\begin{array}{c}22(3) \\
105(20)\end{array}$ & $\begin{array}{c}63(4) \\
157(17)\end{array}$ & $\begin{array}{r}0(0) \\
58(3)\end{array}$ & $\begin{array}{c}71(1) \\
231(12)\end{array}$ & $\begin{array}{r}31(12) \\
120(75)\end{array}$ \\
\hline
\end{tabular}

†Currently married to a husband in social class I-V. (Standardised mortality ratios are based on comparison with all ever married women; age standardisation was performed.)

$\neq$ Parity refers to number of live births in marriage, as recorded in 1971 census:

increasing parity. Mortality from cancer of the colon was above average in women of high parity, though the trend across parity groups was irregular. Mortality from breast cancer and from bladder and kidney cancers tended to decrease with increasing parity, but the trends were significant only when nulliparous women were included. The decreasing trend for mortality from all malignancies with increasing parity was also significant only when nulliparous women were included in the analysis (table II). No clear trends were evident for gastric and brain cancer.

The trends in mortality for selected causes in relation to parity within the non-manual (I, II, IIIN) and manual (IIIM, IV, V) social class groups were compared by taking mortality in all women who had ever been married as the standard (table III). The number of deaths was often small, but women whose husbands were in the manual classes generally had higher mortality ratios than those whose husbands were in the non-manual classes.

Nulliparous women had an all cause standardised mortality ratio of 86 in the non-manual classes compared with a standardised mortality ratio of 118 in the manual; and similar differences were evident at each parity level. Mortality from breast cancer was higher among the parous wives of non-manual workers than among the wives of manual workers (though mortality from breast cancer in nulliparous women showed the reverse). Diabetes mellitus did not show great differences in mortality ratios or trends with parity between women in the manual and non-manual classes.

\section{Discussion}

This is the first systematic analysis of mortality in relation to parity in a national sample of women where the findings have been adjusted for social class. Although the number of deaths from specific causes was often small, the data indicate that mortality from certain causes is related to the number of liveborn children and cannot be explained by social class (as indicated by the husband's occupation). For the nonmalignant diseases the only statistically significant result was the relation between the number of children and mortality from diabetes mellitus. Though based on few deaths, the trend with parity was highly significant, and women with five or more children had a mortality ratio five times that of women who had only one child (standardised mortality ratios of 274 and 
57 respectively). The mortality from diseases of the circulatory system, especially hypertension and ischaemic heart disease, also increased with parity, but the trends were not significant and the relative increase in mortality not large. For example, the mortality from all circulatory diseases was less than $20 \%$ higher in women with five or more children than in those with one child (standardised mortality ratios 121 and 104 respectively).

The association between diabetes mellitus and parity found here has been observed previously, ${ }^{4}{ }^{12}$ although not all reports have been consistent. ${ }^{12}$ Ischaemic heart disease has been found to increase with parity in two series of hospital patients from the United States. ${ }^{i x}$ In the United States ${ }^{i x}$ and in Sweden ${ }^{14}$ the number of abortions a woman had was more strongly related to ischaemic heart disease than parity itself. Information about abortions was not collected for this study, but the data were consistent with the risk of ischaemic heart disease increasing with parity.

The only cancer whose mortality increased significantly with number of children was cervical cancer. Such an association has been found consistently, although adjustment for social class has not always been performed. ${ }^{1 \cdot 3}$ The relation may well be a direct effect of childbearing since it persists after adjusting for the number of sexual partners a woman has had, which is itself predictive of the disease. ${ }^{15}$

Studies from Canada,' Czechoslovakia, ${ }^{2}$ and England and Wales ${ }^{16}$ on the relation between parity and cancer at various sites have all reported a decreasing trend in cancers of the breast, ovary, and endometrium with increasing parity, although only the Canadian data were adjusted for social class. Our findings for breast cancer broadly agree with the Canadian findings. In Canada the trend for breast cancer with parity could be accounted for by the earlier age of first pregnancy in the multiparous women, ' but others have found that the trend with parity persisted even after adjusting for age at first birth. ${ }^{17}$

The trends in the longitudinal study population for ovarian cancer and for endometrial cancer (most of the category described as other uterine cancer) did not show a clear decline with increasing numbers of live births. This finding might have been due to the small numbers, but the use of oral contraceptives or postmenopausal hormone replacement therapy might have altered the epidemiological patterns of these malignancies. ${ }^{18}$ As the women were aged 16-59 in 1971 some of them may have used these hormonal preparations.

Inconsistent associations have been reported elsewhere between parity and cancers of the digestive organs. ${ }^{12+6}$ In the longitudinal study data there was no association between parity and stomach, colon, or other digestive tract cancers, except oesophageal cancer. Mortality from oesophageal cancer in our study was found to decrease significantly with the number of live births, as was mortality from bladder and kidney cancer when nulliparas were included in the analysis. These associations have not been reported before and might be chance findings since many statistical tests were performed and similar results have not been found elsewhere.

Even if childbearing had no long term effects on health we might expect that nulliparity would predict high mortality and multiparity low mortality. Not only do certain chronic diseases lower fertility, ${ }^{19}$ but married women in poor health may restrict their family size. 21 Thus the higher mortality among nulliparous women observed here and elsewhere ${ }^{21}$ might have been due to selection. Another explanation for the different mortality patterns of nulliparous and parous married women may arise from their differing lifestyles and patterns of employment, nulliparous women being more likely to work outside the home and, for example, encounter harmful exposures in the workplace. Obesity has been related to parity, ${ }^{22}$ although not consistently, as well as to diabetes and circulatory disease. No information on obesity was available for this study, though others have shown that the association of diabetes and parity persists after controlling for obesity. ${ }^{13}$ If smoking were confounding some associations adjusting for social class should in part control for smoking since the prevalence of smoking is higher in manual than in non-manual classes, as is mortality from lung cancer (table III). Finally, mortality need not necessarily reflect incidence patterns, and it may be that multiparous women suffer different case fatality rates than women with few children.

Some of the conditions whose incidence alters during the course of pregnancy are the ones which show long term associations with multiparity. Diabetes is the clearest example of this. Pregnancy exaggerates the metabolic defect of diabetes and may cause it to appear first as gestational diabetes. ${ }^{23}$ Atherogenic lipid patterns are induced by pregnancy, ${ }^{2+}$ and repeated pregnancies might lead to atherosclerosis and myocardial infarction. Toxaemia of pregnancy might also increase the long term risks of hypertensive disease and its complications. While endogenous hormonal influences probably underlie the associations between parity and cancers of the hormone sensitive tissues such as the breast, ovary, and endometrium, hormonal changes may underlie other associations. The similarity of the long term effects of oral contraceptives and of pregnancy on health suggests that this might be so. ${ }^{3}$

In conclusion, these data indicate that a woman's childbearing history has some role in determining her subsequent disease pattern. A woman's health also predetermines her childbearing pattern, and the high mortality from most causes among nulliparous women is probably due to selective factors. Multiparity is associated with an excess risk of cervical cancer and a reduced risk of breast cancer. The tendency for mortality from conditions such as diabetes mellitus and some circulatory diseases to increase with increasing numbers of live births suggests that there may also be residual and cumulative effects of childbearing on conditions other than cancers of the reproductive organs.

We thank Mr M Rosato, Dr P Goldblatt, and Ms H Pugh of the Social Statistics Research Unit for help with computing. AG was supported by a Neil Hamilton Fairley Fellowship from the National Health and Medical Research Council of Australia.

(C) Crown copyright.

1 Miller AB, Barclay THC, Choi NW, et al. A study of cancer, parity and age at first pregnancy. $\mathrm{J}$ Chronic Dis 1980;33:595-605.

2 Plesko I, Preston-Martin S, Day NE, Tzonou A, Dimitrova E, Somogyi J. Parity and cancer risk in Slovakia. Int $\mathcal{F}$ Cancer 1985;36:529-33.

3 Beral V. Long term effects of childbearing on health. $\mathcal{I}$ Epidemiol Community Health 1985;39:343-6.

4 Potter JD, McMichael AJ. Large bowel cancer in women in relation to reproductive and hormonal factors. A case-control s:udy. $7 N C I$ 1983;71 703-9.

5 Weiss NS, Daling JR, Chow WH. Incidence of cancer of the large bowel in women in relation to reproductive and hormonal factors. $\mathcal{F} C I$ 1981;67: $57-67$.

6 Byers $\mathrm{T}$, Graham S, Swanson M. Parity and colorectal cancer risk in women INCI 1982;69:1059-62.

7 Beard CM, Fuster V, Annegers JF. Reproductive history in women with coronary heart disease. A case-control study. Am J Epidemiol 1984;120: coronary

8 Winkelstein W, Stenchever MA, Lilienfeld AM. Occurrence of pregnancy, abortion, and artificial menopause among women with coronary artery disease: a preliminary study. $\mathcal{f}$ Chronic Dis 1958;7:273-86.

9 Fitzgerald MG, Malins JM, O'Sullivan DJ, Wall M. The effect of sex and parity on incidence of diabetes mellitus. Qf Med 1961;30:57-70.

10 Fox AJ, Goldblatt PO. Socio-demographic mortalitv differentials: longitudinal study 1971-75. London: HMSO, 1982. (Series LS, No 1.)

11 Mantel N. Chi-squared tests with one degree of freedom. Extension of the Mantel-Haenszel procedure. Journal of the American Statistical Association 1963;58:690-700.

12 Pvke DA. Parity and the incidence of diabetes. Lancet 1956;i:818-21. 
13 West KM. Epidemiology of diabetes and its rascular lesions. New York: Elsevier, 1978:221-4

14 Bengstrom C, Rybo G, Westerberg H. Number of pregnancies, use of oral contraceptives and menopausal age in women with ischaemic heart disease compared to a population sample of women. Acta Med Scand [Suppl] 1973;549:75-81.

15 Brinton LA, Hamman RF, Huggins GR, et al. Sexual and reproductive risk factors for invasive squamous cell cervical cancer. $7 N C I$ 1987;79:23-30

16 Beral V. Parity and susceptibility to cancer. In: Fetal antigens and cancer. London: Pitman, 1983:182-203. (Ciba Foundation Symposium 96.)

17 Kvale G, Heuch I, Elde GE. A prospective study of reproductive factors and breast cancer. I. Parity. Am J Epidemiol 1987:126:831-41.

18 Scott JS Sex hormones and gynaecologicat ancer.BrMed f 1982:284:1657-8.
19 Fraga A, Mintz G, Orozoco J, Orozoco JH. Sterility and fertility rates, fetal wastage and maternal morbidity in systemic lupus erythematosus. 7 Rheumatol 1974;1:293-8.

20 Cartwright A. How many children? London: Routledge and Kegan Paul, 1976:96.

21 Dorn H. Cancer and marital status. Hum Biol 1943;15:73-9.

22 Heliovaara M, Aromaa A. Parity and obesity. F Epidemiol Community Health 1981;35:197-9.

23 Freinkel N. Of pregnancy and progeny. Diabetes 1980;29:1023-35.

24 Oliver MF, Boyd GS. Plasma lipid and serum lipoprotein patterns during pregnancy and puerperium. Clin $S_{c i} 1985 ; 14: 15-23$.

(Accepled 10 Mav 1988

\section{Predictive value of oxygen saturation in emergency evaluation of asthmatic children}

\author{
Gary C Geelhoed, Louis I Landau, \\ Peter N LeSouëf
}

Princess Margaret Hospital for Children,

Box D184 GPO, Perth, Western Australia

Australia 6008

Gary C Geelhoed, FRACP, research fellow in respiratory medicine

Louis I Landau, FRACP, professor of paediatrics

Peter N LeSouëf, FRACP, director, department of

respiratory medicine

Correspondence to:

Dr Geelhoed.

Asthma is the most common respiratory condition in patients who present to emergency departments.' As hypoxia is common in asthma ${ }^{2}$ we reasoned that the severity of an attack might be reflected by the degree of arterial oxygen saturation. This may now be measured simply, non-invasively, and reliably by pulse oximetry. ${ }^{3+}$

We undertook this study to assess the clinical usefulness of oxygen saturation as an objective measure of the-severity of asthma in the emergency department and as a predictor of outcome.

\section{Patients, methods, and results}

We studied 52 patients ( 31 male, 21 female; mean age 6 (range 2-14) years) who presented to an emergency department with acute asthma. All received salbutamol aerosol $(0.03 \mathrm{ml} / \mathrm{kg}$ of a $0.5 \%$ solution to a maximum of $1 \mathrm{ml}$ made up to $2 \mathrm{ml}$ with normal saline) given by an Inspiron 002220 nebuliser driven by 6 litres of air a minute. Assessments and treatments were performed by staff unaware of the results of measuring arterial oxygen saturation. Baseline saturation and saturation at 30 minutes after nebulisation started were measured with an Ohmeda Biox III oximeter (Ohmeda Bioximetry Technology Inc, Boulder, Colorado).

Parents of children who were sent home were contacted five days later and asked if their child had presented again with asthma for medical care. If the answer was "no" parents were asked: "Were you happy with your child's condition following your visit to the emergency department?" For those sent home a favourable course was defined as not presenting again for medical care and parents answering "yes" to the second question. We noted those children admitted who received intravenous treatment. Results are reported as means (SD) and were analysed by Student's $t$ test.

Of the 24 children sent home, eight presented again for medical care, and the parents of three others were not happy with their child's condition after leaving the emergency department. Figure (a) shows the arterial oxygen saturation at presentation for all these groups. The initial saturation of those who presented once $(93.5(4.4) \%)$ was higher than that of those who presented twice $(89 \cdot 4(2 \cdot 0) \%)(\mathrm{p}<0.05)$. At 30 minutes no difference was noted between those presenting once $(93.9(2.8) \%)$ and those presenting twice $(92.6$ $(1.5) \%$ ) (figure (b)). Only those who presented twice showed a significant increase in arterial oxygen saturation from baseline to 30 minutes after nebulisation $(\mathrm{p}<0.01)$.

The initial arterial oxygen saturation was highly predictive of outcome. Saturation of $91 \%$ was found to discriminate between a favourable and an unfavour-
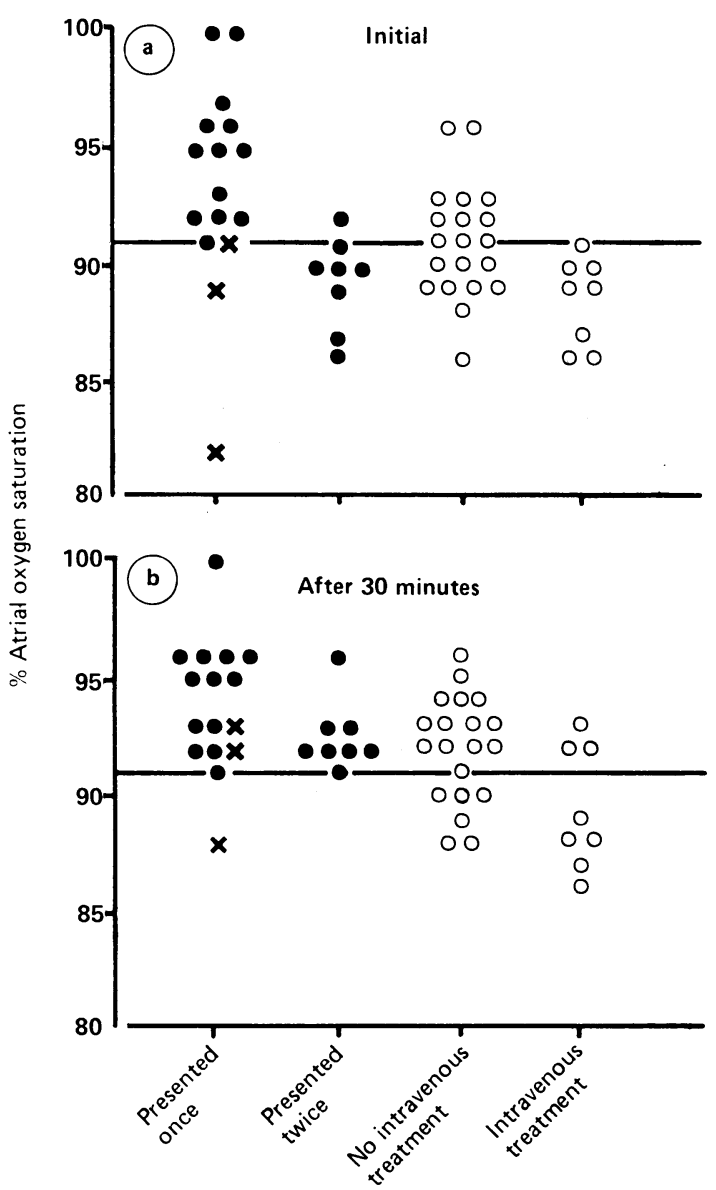

Arterial oxygen saturation of 52 children (a) before and (b) 30 minutes after nebulisation. $\quad=$ Sent home. $\bigcirc=$ Admitted. $\times=$ Parents unhappy

able outcome. Of 13 children sent home with an initial saturation of greater than $91 \%$, only one presented again. Eleven children who had an initial saturation of $91 \%$ or less were sent home; all but one of these children had an unfavourable outcome.

\section{Comment}

Several important clinical points arise from these data. Firstly, patients who have low initial arterial oxygen saturation, even if they respond to salbutamol, should always be treated with concern. Some of these children may be better managed as inpatients or need additional drug treatment if sent home. Secondly, an increase in saturation in response to nebulised salbutamol in the emergency department does not necessarily correlate well with a good outcome.

We emphasise that the initial saturation should not be used as the sole criterion for judging the need for admission, as some children who have severe asthma are often admitted for stabilisation of management. In our study the group who showed the best response to bronchodilator treatment had a poor outcome. We therefore suggest that when judging the severity of an asthmatic attack in children doctors should give more consideration to the initial arterial oxygen saturation 